\title{
Variabilidade genética em linhagens de milho nas características relacionadas com a produtividade de silagem
}

\author{
Maximilian de Souza Gomes ${ }^{(1)}$, Renzo Garcia Von Pinho(2), Magno Antonio Patto Ramalho ${ }^{(3)}$, \\ Denys Vitor Ferreira ${ }^{(2)}$ e André Humberto de Brito ${ }^{(2)}$
}

\begin{abstract}
(1)Faculdade de Engenharia e Agronomia de Passos, Av. Juca Stockler, 1130, CEP 37900-106 Passos, MG. E-mail: maxsgomes@uol.com.br (2)Universidade Federal de Lavras (Ufla), Dep. de Agricultura, Caixa Postal 37, CEP 37200-000 Lavras, MG. E-mail: renzo@ufla.br (3)Ufla, Dep. de Biologia. E-mail: magnoapr@ufla.br
\end{abstract}

\begin{abstract}
Resumo - Em programas que visam à obtenção de híbridos, a ênfase deve ser no desenvolvimento de cultivares com maior produtividade de matéria seca e digestibilidade da silagem e que apresentem variação entre si em relação a esses caracteres. O objetivo deste trabalho foi avaliar a variabilidade genética de linhagens de milho quanto a características relacionadas à produção de silagem. Foram semeadas 36 linhagens em duas épocas (novembro e dezembro), no delineamento de látice simples 6x6. As plantas foram colhidas no estádio de grãos farináceo-duro e ensiladas por 100 dias. Foram determinadas as variáveis produtividade de matéria seca e degradabilidade in situ da matéria seca, em dois períodos de incubação das silagens, 24 e 96 horas, e porcentagem de fibra em detergente neutro. Houve variabilidade genética nos caracteres relacionados à produtividade $\mathrm{e}$ qualidade da silagem. $\mathrm{O}$ comportamento das linhagens em relação à degradabilidade da matéria seca e fibra em detergente neutro foi semelhante nas diferentes épocas de semeadura. A herdabilidade estimada na média das duas épocas de semeadura em relação à degradabilidade da matéria seca foi superior a 80\%, evidenciando a possibilidade de êxito no processo de seleção. A alta correlação entre os dois períodos de incubação indica a possibilidade de se avaliar a degradabilidade da matéria seca no período de 24 horas, permitindo maior eficiência e rapidez.
\end{abstract}

Termos para indexação: Zea mays, degradabilidade in situ, herdabilidade, correlação.

\section{Genetic variability in maize lines for characteristics related to silage yield}

\begin{abstract}
Programs to obtain hybrids, should emphasize cultivars with great dry matter yield, silage digestibility and the variation among cultivars in relation to these characteristics. The objective of this work was to evaluate genetic variability of maize lines for characteristics related to silage yield. Thirty-six lines were sown in two periods, November and December, in a simple 6x6 lattice design. Plants were harvested at the hard-farinose grain stage and insiled for 100 days. Dry matter yield and in situ dry matter degradability in silage incubation periods of 24 and 96 hours and percent of fiber in neutral detergent were assessed. There was genetic variability for the traits related to yield and silage quality. The line performance for dry matter degradability and fiber in neutral detergent was similar between sowing periods. The heritability estimated on the mean of the two sowing periods for dry matter degradability was greater than $80 \%$ showing the possibility of success in the selection process. The high correlation between incubation periods indicated the possibility of assessing dry matter degradability in 24 hours, offering greater efficiency and speed.
\end{abstract}

Index terms: Zea mays, in situ degradability, heritability, correlation.

\section{Introdução}

A exploração da bovinocultura de leite ou de carne exige alta produtividade do rebanho durante todo o ano. Em regiões cujo outono-inverno é caracterizado por escassez de precipitação pluvial, a produção e a qualidade da forragem diminuem, o que pode acarretar perda de peso e menor produtividade de leite nos rebanhos. Nes- ta época do ano, torna-se necessária a suplementação da alimentação dos animais, e uma das principais fontes de volumoso nessa suplementação é a silagem de milho.

Nos sistemas de criação intensivos da bovinocultura de leite e de carne, a utilização de animais melhorados é comum, e para que se possa explorar todo potencial genético desses rebanhos é imprescindível que a silagem 
de milho seja de alta qualidade. A maioria dos programas de melhoramento de milho conduzidos no país não dá muita ênfase ao desenvolvimento de cultivares para produção de silagem. Os melhores híbridos, os que produzem mais grãos, são também recomendados para a produção de silagem. Entretanto, Coors et al. (1994) mostraram que nem sempre as melhores cultivares para a produção de grãos são as de melhor digestibilidade da planta inteira.

Entre os fatores que afetam a qualidade da silagem, a digestibilidade da matéria seca é um dos mais importantes. Esta característica permite uma indicação mais segura sobre o valor nutricional da cultivar de milho a ser ensilada. Diversos trabalhos demonstraram a relação entre a digestibilidade da silagem e o desempenho animal (Barrière et al., 1992; Hunt et al., 1992), indicando que híbridos de milho mais digestíveis resultam em uma melhora na eficiência da alimentação e, conseqüentemente, um melhor desempenho dos animais. Assim, a ênfase nos programas para obtenção de híbridos deve ser direcionada ao desenvolvimento de cultivares com maior digestibilidade da silagem.

Um dos métodos utilizados na avaliação da digestibilidade da silagem é a degradabilidade in situ da matéria seca, que avalia a degradação potencial e efetiva da forragem e tem como principal vantagem processar simultaneamente um grande número de amostras (Oliveira et al., 1999). Na exploração adequada do germoplasma de um programa de melhoramento, o conhecimento da variabilidade genética entre as linhagens é fundamental, pois permite antever a possibilidade de ganhos com a seleção e também planejar cruzamentos que maximizem a heterose.

O objetivo deste trabalho foi avaliar a variabilidade genética de linhagens de milho quanto a características relacionadas à produção de silagem.

\section{Material e Métodos}

Foram avaliadas 36 linhagens $S_{8}$ de milho, provenientes de diferentes populações, tomadas aleatoriamente de um banco de germoplasma contendo aproximadamente mil linhagens, cedidas pela empresa GeneSeeds - Recursos Genéticos em Milho Ltda. Os experimentos para avaliação das linhagens foram instalados em duas épocas de semeadura, novembro e dezembro, na área experimental da Universidade Federal de Lavras (Ufla), Minas Gerais.
O delineamento experimental utilizado foi o látice simples 6x6. As parcelas foram constituídas de duas linhas de 4 metros, espaçadas de $0,8 \mathrm{~m}$ e com densidade de 55.000 plantas ha-1. No momento da semeadura foram aplicados, em ambas as épocas de semeadura, $400 \mathrm{~kg} \mathrm{ha}^{-1}$ de adubo da formulação 8-28-16+0,5\% de zinco. Quando as plantas atingiram entre quatro e cinco folhas, aplicaram-se em cobertura $300 \mathrm{~kg} \mathrm{ha}^{-1}$ da formulação 20-00-20. A segunda adubação de cobertura foi realizada quando as plantas atingiram entre oito e nove folhas, com a aplicação de $130 \mathrm{~kg} \mathrm{ha}^{-1}$ de uréia. Foi aplicado via foliar o produto comercial Arrank, aos 30 dias após semeadura, na dosagem de $2 \mathrm{~L} \mathrm{ha}^{-1}$. Os tratos culturais realizados, bem como o combate de pragas, foram executados nas épocas adequadas, de acordo com as necessidades da cultura.

As plantas das parcelas foram colhidas, cortando-as a $20 \mathrm{~cm}$ do solo, à medida que os grãos das espigas de cada linhagem apresentavam-se no ponto denominado de meia linha de leite (Fancelli \& Dourado Neto, 2000), com a matéria seca entre $30 \%$ e $40 \%$. Por ocasião da colheita, as plantas foram pesadas para a determinação da produtividade de matéria verde. Posteriormente, as plantas de cada parcela foram trituradas em picadeira e homogeneizadas para a retirada de duas amostras. A primeira amostra $(900 \mathrm{~g})$ foi secada em estufa de ventilação forçada a uma temperatura de $55^{\circ} \mathrm{C}$, até obter peso constante, e posteriormente moída em moinho tipo Willey, com peneira de $5 \mathrm{~mm}$ para a determinação da porcentagem de matéria seca (MS) em estufa a $105^{\circ} \mathrm{C}$. Assim, a produtividade de MS foi estimada por meio da produtividade de massa de matéria verde multiplicada pela porcentagem de $\mathrm{MS}$ a $105^{\circ} \mathrm{C}$.

Uma segunda amostra foi colocada em silos experimentais de PVC, cilíndricos, com aproximadamente $45 \mathrm{~cm}$ de altura e $10 \mathrm{~cm}$ de diâmetro, que foram armazenados em local coberto e temperatura ambiente. Após 100 dias, as silagens foram retiradas dos silos e homogeneizadas, extraindo-se, posteriormente, uma amostra de 900 g. Seguiu-se o mesmo procedimento de secagem em estufa a $55^{\circ} \mathrm{C}$ até a amostra atingir o peso constante. Essa amostra foi dividida em duas partes: uma parte moída com peneira de $5 \mathrm{~mm}$ e a outra, com peneira de $1 \mathrm{~mm}$. O material moído a $5 \mathrm{~mm}$ foi utilizado na condução do ensaio de degradabilidade in situ, enquanto a outra parte, moída com peneira de $1 \mathrm{~mm}$, foi utilizada na determinação da porcentagem de fibra em detergente neutro, segundo Van Soest et al. (1991). 
A degradabilidade in situ das silagens de todas as linhagens foi realizada segundo Pereira (1997). Essas análises foram efetuadas por meio de incubação ruminal em cinco vacas, três da raça Holandesa e duas da raça Jersey, não lactantes, não gestantes e com cânula ruminal, em períodos de 24 e 96 horas, utilizando-se saquinhos, em que os animais receberam todas as amostras da massa de matéria seca das silagens provenientes das parcelas dos dois experimentos. Em cada saquinho foram colocados $5 \mathrm{~g}$ de amostra secada a $55^{\circ} \mathrm{C}$, correspondendo a $18,5 \mathrm{mg} \mathrm{cm}^{-2}$.

Os animais foram submetidos a um processo de adaptação durante quinze dias antes do início da incubação, com o objetivo de obter boas condições ruminais para a realização da degradabilidade in situ. Nessa adaptação, foi fornecida uma dieta à base de fubá de milho em torno de $2 \mathrm{~kg}$ por dia por animal e livre acesso ao pastejo. Durante a incubação, os animais foram mantidos em baias separadas, submetidos a uma dieta à base de farelo de milho, em torno de $4 \mathrm{~kg}$ por dia por animal, fornecida duas vezes ao dia, e capim picado no cocho à vontade.

O método adotado no controle de tempo dos saquinhos no rúmen constituiu-se na colocação daqueles que permaneceriam mais tempo no rúmen, retirando todos de uma só vez. Os saquinhos pertencentes a cada tempo foram colocados dentro de um saco de filó com a adição de pesos para mantê-los imersos no rúmen. O número de saquinhos por animal por tempo foi de 144 unidades, o que corresponde ao número de parcelas em cada época de semeadura (72) multiplicado pelo número de épocas (duas).

Após serem retirados do rúmen, os saquinhos foram imediatamente colocados em água gelada para a paralisação do processo de degradação. Em seguida, foram lavados com leve agitação em sistema de tanque com hélice agitadora, renovando-se a água até que ela se apresentasse transparente. Posteriormente, foram colocados em estufa a $55^{\circ} \mathrm{C}$ até peso constante, e logo após foram pesados. Pela diferença entre essa pesagem e a efetuada antes de incubar os materiais, determinou-se a quantidade de matéria seca degradada no rúmen, expressa em porcentagem de matéria seca degradável. A porcentagem de fibra em detergente neutro foi obtida segundo método descrito por Van Soest et al. (1991).

Foram realizadas, inicialmente, as análises de variância individuais de cada época de semeadura de todas as características avaliadas e da degradabilidade in situ da matéria seca, por tempo de incubação. Posteriormente, foram realizadas análises conjuntas envolvendo as duas épocas de semeadura e os dois tempos de incubação no caso da degradabilidade in situ da matéria seca.

Com base nas análises de variância foram estimadas as variâncias genéticas, fenotípicas e das interações entre as linhagens e as épocas de semeadura. Estimaram-se as herdabilidades $\left(\mathrm{h}^{2}\right)$ no sentido amplo, na média das linhagens, conforme Ramalho et al. (1993):

$\mathrm{h}_{\mathrm{m}}^{2}=\frac{\sigma_{\mathrm{g}}^{2}}{\sigma_{\mathrm{f}}^{2}}$,

em que $\mathrm{h}^{2} \mathrm{~m}$ é a herdabilidade média estimada; $\sigma_{\mathrm{g}}^{2}$ é a variância genética entre as linhagens; $\sigma_{\mathrm{f}}^{2}$ é a variância fenotípica entre as linhagens.

Foram estimadas as correlações genéticas entre os caracteres, de acordo com equação de Ramalho et al. (2000):

$r_{g(x y)}=\frac{\operatorname{COV}_{(x y)}}{\left(\sigma_{g(x)}^{2} \sigma_{g(y)}^{2}\right)^{1 / 2}}$,

em que $r_{\mathrm{g}(\mathrm{xy})}$ é a correlação genética entre as características x e y; $\mathrm{COV}_{(\mathrm{xy})}$ é a covariância entre as características x e y; $\sigma_{\mathrm{g}(\mathrm{x})}^{2}$ é a variância genética da característica $\mathrm{x} ; \sigma_{\mathrm{g}(\mathrm{y})}^{2}$ é a variância genética da característica y.

\section{Resultados e Discussão}

Houve diferença significativa entre as linhagens em todas as características, nas duas épocas de semeadura utilizadas. Após verificada a homogeneidade de variância residual (teste de Bartlett), procedeu-se à análise de variância conjunta envolvendo as duas épocas de semeadura (Ramalho et al., 2000).

$\mathrm{Na}$ análise conjunta, verificou-se, em relação à produtividade de matéria seca das linhagens, diferença significativa quanto a linhagens e quanto à interação entre linhagens e épocas de semeadura. Em relação à diferença entre as linhagens, a variação foi de 5,84 a $15,68 \mathrm{tha}^{-1}$ na primeira época de semeadura, ou seja, uma amplitude de 9,84 t ha-1 (Figura 1). Já na segunda época de semeadura, a variação foi de 5,49 a $11,03 \mathrm{t} \mathrm{ha}^{-1} \mathrm{e}$ amplitude de 5,54 $\mathrm{t} \mathrm{ha}^{-1}$ de massa de matéria seca (Figura 1). As produtividades podem ser consideradas elevadas por se tratar de um grupo de linhagens endógamas de milho, em que o vigor é baixo.

A ocorrência da interação entre linhagens e épocas de semeadura na produtividade de matéria seca indica que o comportamento das linhagens não foi coincidente nas duas épocas. Fonseca (2000) também observou interação significativa nesse caráter ao avaliar cultivares comerciais de milho em diferentes épocas de seme- 
adura na região. Contudo, Ramalho (1999) verificou pequena importância dessa interação quando avaliou famílias de meios-irmãos também no sul de Minas Gerais.
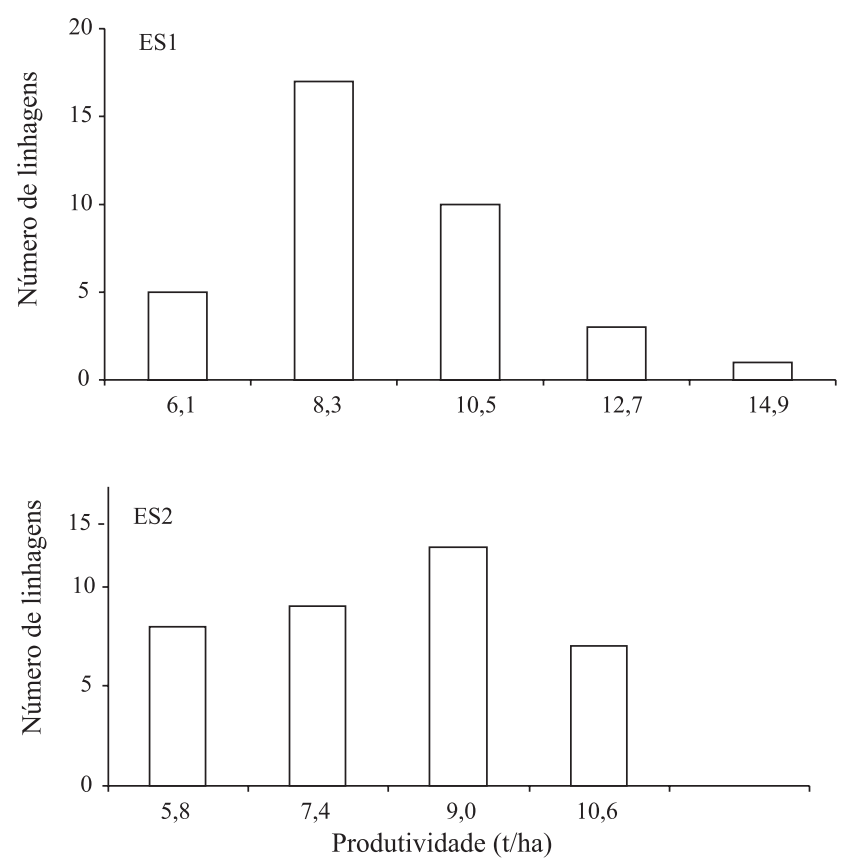

Figura 1. Distribuição de frequiência da produtividade de matéria seca de 36 linhagens de milho avaliadas na primeira (ES1) e segunda (ES2) época de semeadura.
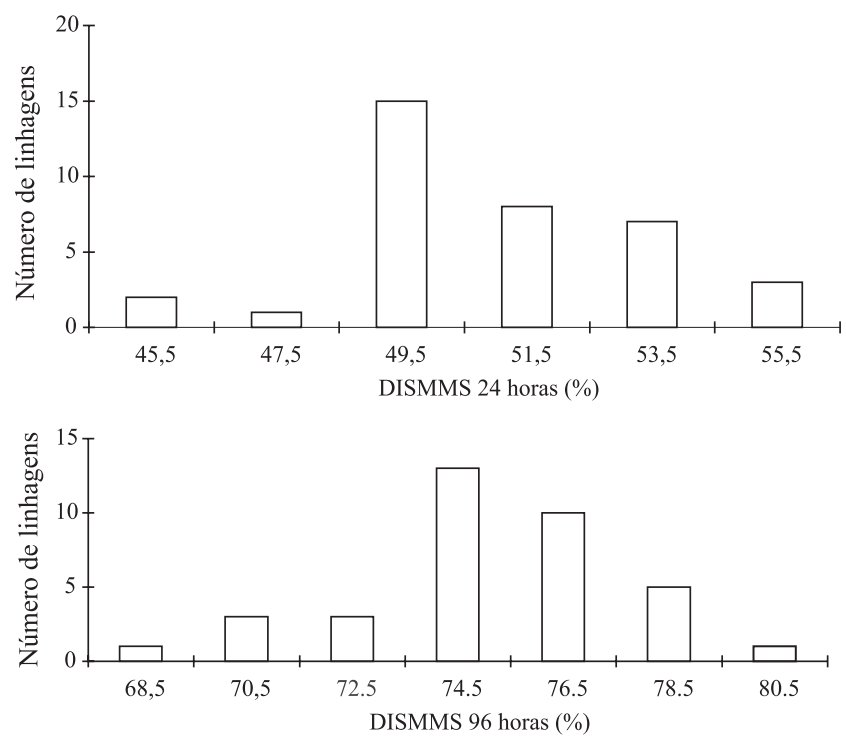

Figura 2. Distribuição de freqüência da degradabilidade in situ da matéria seca (DISMS) em 24 e 96 horas de incubação, de 36 linhagens de milho avaliadas em duas épocas de semeadura.
$\mathrm{Na}$ degradabilidade in situ da matéria seca da silagem (DISMS), foram realizadas as análises conjuntas por época de semeadura e por tempo de incubação separadamente e, assim como nas análises individuais, foram detectadas diferenças significativas $(\mathrm{P} \leq 0,01)$ entre as linhagens. Pela análise conjunta para DISMS, envolvendo as duas épocas de semeadura e os dois tempos de incubação simultaneamente, constatou-se diferença significativa $(\mathrm{P} \leq 0,05)$ em relação às épocas de semeadura, tempos de incubação e linhagens.

$\mathrm{O}$ atraso na época de semeadura provocou um decréscimo na digestibilidade média das silagens, concordando com Villela (2001). Os resultados evidenciam a importância da semeadura do milho na época recomendada, não só objetivando maiores produtividades de silagem, como já constatado em outros trabalhos (Keplin \& Santos, 1996; Villela, 2001), mas também objetivando silagem de melhor qualidade.

Quanto aos períodos de incubação, a diferença significativa observada era esperada, visto que no tempo de 96 horas, as silagens permaneceram por um período maior no rúmem sofrendo portanto, maior degradação. Houve diferenças significativas na degradabilidade da silagem, entretanto, a interação entre linhagens e épocas de semeadura não foi significativa para esta característica, indicando que o comportamento das linhagens foi consistente nas duas épocas, ou seja, a degradabilidade das linhagens é alterada em magnitudes semelhantes. A variabilidade entre as linhagens quanto a essa característica é mostrada pelas distribuições de freqüência, em que o comportamento das linhagens está exposto nos dois períodos de incubação (Figura 2). A variação da degradabilidade in situ no período de 24 horas de incubação foi de 44,7 a 55,6\% e após 96 horas de incubação, foi de $68,3 \%$ a $81,2 \%$. Villela (2001) também constatou variações semelhantes e enfatizou o potencial a ser explorado pelo melhoramento desta característica.

Johnson et al. (1985) estimou que um acréscimo de $2 \%$ na digestibilidade da matéria orgânica da silagem pode representar, para uma vaca com $600 \mathrm{~kg}$ de peso e produtividade de $25 \mathrm{~kg}$ de leite (4\% de gordura) por dia, um acréscimo de $596 \mathrm{~g}$ de leite. O mesmo autor avaliou a digestibilidade da matéria seca de nove cultivares de milho durante dois anos e observou variação de 4,2\%.

Outra característica importante na avaliação da qualidade da silagem é a porcentagem de fibra em detergente neutro (FDN), a qual determina a quantidade de fibra, correspondente às frações de lignina, celulose e 
hemicelulose presentes na silagem. Quanto menor a FDN, maior a digestibilidade da silagem. A análise conjunta, envolvendo as duas épocas de semeadura, revelou diferenças significativas $(\mathrm{P} \leq 0,01)$ entre as linhagens e épocas de semeadura. A existência de variabilidade entre as linhagens nessa característica é ilustrada por distribuições de freqüência (Figura 3). Já a inexistência de interação entre linhagens e épocas de semeadura indica novamente que o comportamento das linhagens foi coincidente nas duas épocas.

A FDN, assim como a DISMS, foi afetada pela época de semeadura. A semeadura realizada mais tarde levou a um aumento na porcentagem de FDN. Esse resultado é coerente com o relatado, visto que aumento na fibra foi acompanhado de redução na degradabilidade da silagem.

Pelas estimativas dos parâmetros genéticos e fenotípicos, considerando a análise conjunta dos dados, foi observada variabilidade genética entre as linhagens nas três características estudadas (Tabela 1).

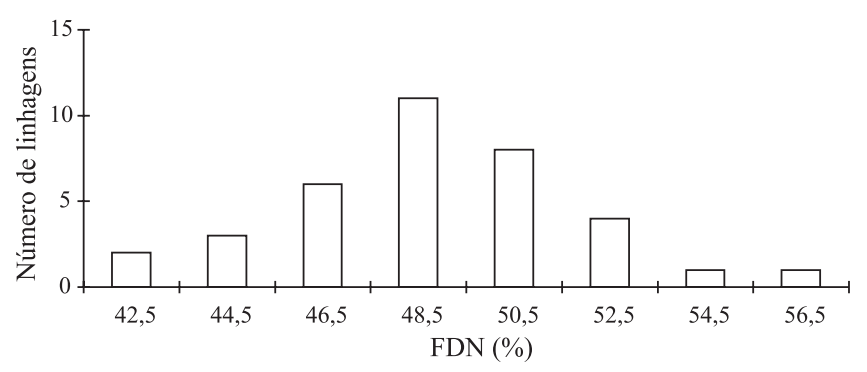

Figura 3. Distribuição de freqüência da porcentagem de fibra em detergente neutro (FDN), de 36 linhagens de milho avaliadas em duas épocas de semeadura.

Tabela 1. Resumo da análise de variância conjunta em relação à produtividade de matéria seca (MS), degradabilidade in situ da matéria seca (DISMS) e porcentagem de fibra em detergente neutro (FDN) e estimativas das variâncias genéticas $\left(\hat{\sigma}_{\mathrm{g}}^{2}\right)$, fenotípicas $\left(\hat{\sigma}_{\mathrm{f}}^{2}\right)$, da interação entre linhagens e épocas $\left(\hat{\sigma}_{\mathrm{gag}}^{2}\right)$ e herdabilidade $\left(\hat{\mathrm{h}}^{2}\right)$ entre linhagens de milho.

\begin{tabular}{lcccc}
\hline Fontes de variação & Graus de liberdade & \multicolumn{3}{c}{ Quadrado médio } \\
\cline { 2 - 5 } & & MS & DISMS & FDN \\
\hline Linhagens (L) & 35 & $6,42^{* *}$ & $195,79^{* *}$ & $35,88^{* *}$ \\
Épocas & 1 & $4,85^{\text {ns }}$ & $74,94^{*}$ & $588,89^{* *}$ \\
L x E & 35 & $5,19^{* *}$ & $37,06^{\text {ns }}$ & $12,19^{\text {ns }}$ \\
Média & & 8,02 & 63,11 & 48,76 \\
CV $(\%)$ & 19,64 & 6,37 & 6,09 \\
\hline$\hat{\sigma}_{g}^{2}$ & & 0,31 & 3,93 & 5,92 \\
$\hat{\sigma}^{2}$ & & 1,61 & 4,89 & 8,97 \\
$\hat{\sigma}^{2}$ & & 1,36 & 0,38 & 1,69 \\
$\left(\hat{\sigma}_{g a}^{2} / \hat{\sigma}_{g}{ }_{g}\right) \times 100$ & & 438,71 & 9,67 & 28,65 \\
$\hat{\mathrm{h}}^{2}(\%)$ & 19,25 & 80,37 & 65,99 \\
\hline
\end{tabular}

A estimativa da variância da interação entre linhagens e épocas de semeadura $\left(\sigma_{\text {ga }}^{2}\right)$ oscilou entre os caracteres. Em virtude das diferenças nas unidades, a fim de comparar sua importância, foi calculada a relação entre a estimativa da interação e a variância das linhagens, isto é, $100\left(\sigma_{\mathrm{ga}}^{2} / \sigma_{\mathrm{g}}^{2}\right)$. No caso da DISMS e FDN, o efeito da interação foi de $9,67 \%$ e $28,55 \%$, respectivamente, e, em relação à produtividade de MS, sua estimativa superou a variância genética entre as linhagens em 4,38 vezes, indicando maior relevância da interação entre linhagens e épocas de semeadura nesse caráter.

A herdabilidade é o melhor parâmetro para se fazer qualquer inferência sobre o sucesso do melhoramento em um dado caráter. $\mathrm{O}$ valor dessa estimativa variou de $19,25 \%$ (MS) a 80,37\% (DISMS) (Tabela 1). Esse resultado revela a existência de variação genética nos três caracteres e a possibilidade de êxito no processo de seleção, principalmente nos caracteres FDN e DISMS, em que foram observadas as maiores estimativas.

Contudo, há escassez de informações a respeito de parâmetros genéticos e fenotípicos dos caracteres associados à produção de forragem. Assim, pode-se inferir que a estimativa de $\mathrm{h}^{2}$ para a MS $(19,25 \%)$ foi inferior à relatada por Ramalho (1999), que avaliou famílias de meios-irmãos e observou estimativas de $\mathrm{h}^{2}$ acima de $60 \%$ no referido caráter. Em relação à porcentagem de FDN, a estimativa de $\mathrm{h}^{2}(65,99 \%)$ foi inferior à observada por Beeghly (1990), que, ao avaliar famílias $S_{1}$ provenientes de quatro populações, encontrou valores superiores a $80 \%$.

Um aspecto importante na seleção de materiais é o conhecimento da relação entre as características que estão sendo avaliadas. Assim, características altamente correlacionadas possibilitam a seleção com base naquela de mais fácil avaliação, permitindo ganho semelhante na outra característica. A correlação entre a DISMS nas duas épocas foi alta e positiva, indicando que o desempenho das linhagens foi coincidente nas duas épocas de avaliação, como já mencionado, e que a época de semeadura não deverá afetar o sucesso da seleção nesse caráter (Tabela 2).

As altas estimativas da correlação entre a DISMS em 24 e 96 horas evidenciam que não houve alteração no desempenho das linhagens em função do tempo de 
Tabela 2. Estimativas das correlações genéticas entre produtividade de matéria seca (MS), degradabilidade in situ de matéria seca (DISMS) nos períodos de 24 horas e 96 horas e porcentagem de fibra em detergente neutro (FDN), em duas épocas de semeadura (ES1 e ES2), de 36 linhagens de milho.

\begin{tabular}{lcccr}
\hline Características & MS & \multicolumn{2}{c}{ DISMS } & FDN \\
\cline { 3 - 4 } & $(\mathrm{ES} 2)$ & $24 \mathrm{H}(\mathrm{ES} 2)$ & $96 \mathrm{H}(\mathrm{ES} 2)$ & $(\mathrm{ES} 2)$ \\
\hline MMS (ES1) & 0,18 & $-0,07$ & 0,05 & 0,17 \\
DISMS 24H (ES1) & 0,28 & 0,82 & 0,69 & $-0,59$ \\
DISMS 96H (ES1) & 0,30 & 0,69 & 0,93 & $-0,63$ \\
FDN (ES1) & $-0,02$ & $-0,32$ & 0,32 & 0,50 \\
\hline
\end{tabular}

incubação. Isto indica que futuros trabalhos utilizando esta característica podem optar pelo menor período de incubação, possibilitando assim a avaliação do dobro de genótipos de milho.

As correlações envolvendo FDN e degradabilidade foram na maioria dos casos negativas. Desse modo, linhagens que apresentaram alta degradabilidade normalmente possuíam baixa porcentagem de FDN, pois tal característica representa uma porção da parte indigestível da forragem. Resultados semelhantes foram obtidos por Wolf et al. (1993), Penati (1995), Argillier et al. (2000) e Fonseca (2000). Isso implica que qualquer um desses caracteres pode ser utilizado, no futuro, durante o processo de seleção inicial de linhagens ou híbridos de milho.

As correlações envolvendo a produtividade de MS com as duas outras características foram, na sua maioria, de baixa magnitude, e em alguns casos negativas. Entretanto, os resultados não excluem a possibilidade de seleção de linhagens que associem boa produtividade de MS e alta digestibilidade da silagem.

\section{Conclusões}

1. Há variabilidade genética entre as linhagens de milho quanto à produtividade e qualidade da silagem.

2. A degradabilidade in situ da matéria seca e a porcentagem de fibra em detergente neutro são pouco influenciadas pela interação entre épocas de semeadura e linhagens.

3. A herdabilidade estimada entre as linhagens para a degradabilidade da silagem é superior a $80 \%$, evidenciando a possibilidade de êxito no processo de seleção.

4. A degradabilidade in situ da matéria seca pode ser avaliada em 24 horas, permitindo maior eficiência e rapidez.

\section{Referências}

ARGILLIER, O.; MÉCHIN, V.; BARRIÈRE, Y. Inbred line evaluation and breeding for digestibility-related traits in forage maize. Crop Science, v.40, p.1596-1600, 2000.

BARRIÈRE, Y.; TRAINEAU, R.; EMILE, J.C. Variation and covariation of silage maize digestibility estimated from digestion trials with sheep. Euphytica, v.59, p.61-72, 1992.

BEEGHLY, H.H. The effect of cell wall constituents in determining resistance of maize to the European corn borer. 1990. 119p. Thesis (Ph.D.) - University of Wisconsin, Madison.

COORS, J.G.; CARTER, P.R.; HUNTER, R.B. Silage corn. In: HALLAUER, A.R. (Ed.). Specialty corns. Boca Raton: CRC Press, 1994. p.305-340.

FANCELli, A.L.; DOURADO NETO, D. Produção de milho. Guaíba: Agropecuária, 2000. 360p.

FONSECA, A.H. Características químicas e agronômicas associadas à degradabilidade da silagem de milho. 2000. 93p. Dissertação (Mestrado) - Universidade Federal de Lavras, Lavras.

HUNT, C.W.; KEZAR, W.; VINANDE, R. Yield, chemical composition, and ruminal fermentability of corn whole plant, ear, and stover as affected by hybrid. Journal of Production Agriculture, v.5, p.286-290, 1992.

JOHNSON, J.C.; MONSON, W.G.; PETTIGREW, W.T. Variation in nutritive value of corn hybrids for silage. Nutrition Reports International, v.32, p.953-958, 1985.

KEPLIN, L.A.S.; SANTOS, I.R. Silagem de milho. Guaíra: Braskalb Agropecuária Brasileira, 1996. 46p.

OLIVEIRA, J.S.; FERREIRA, R.P. de; CRUZ, C.D.; PEREIRA, A.V.; LOPES, F.C.F. Adaptabilidade e estabilidade de cultivares de milho para silagem em relação à produção de matéria seca degradável no rúmen. Revista Brasileira de Zootecnia, v.28, p.230-234, 1999.

PENATI, M.A. Relação de alguns parâmetros agronômicos e bromatológicos de híbridos de milho (Zea mays L.) com a produção, digestibilidade e teor de matéria seca da planta. 1995. 97p. Dissertação (Mestrado) - Escola Superior de Agricultura Luiz de Queiroz, Piracicaba.

PEREIRA, M.N. Responses of lactating cows to dietary fiber from alfafa or cereal by products. 1997. 186p. Thesis (Ph.D.) University of Winconsin, Madison.

RAMALHO, A.R. Comportamento de famílias de meios-irmãos em diferentes épocas de semeadura visando à produção de forragem de milho. 1999. 78p. Dissertação (Mestrado) Universidade federal de Lavras, Lavras.

RAMALHO, M.A.P.; FERREIRA, D.F.; OLIVEIRA, A.C. de. A experimentação em genética e melhoramento de plantas. Lavras: Ufla, 2000. 326p. 
RAMALHO, M.A.P.; SANTOS, J.B. dos; ZIMMERMANN, M.J. de O. Genética quantitativa em plantas autógamas: aplicações ao melhoramento do feijoeiro. Goiânia: UFG, 1993. 271p.

VAN SOEST, P.J.; ROBERTSON, J.B.; LEWIS, B.A. Methods for dietary fiber, neutral detergent fiber, and nonstarch polysaccharides in relation to animal nutrition. Journal of Dairy Science, v.74, p.3583-3597, 1991.
VILLELA, T.E.A. Época de semeadura e de corte de plantas de milho para silagem. 2001. 86p. Dissertação (Mestrado) Universidade Federal de Lavras, Lavras.

WOLF, D.P.; COORS, J.G.; ALBRECHT, K.A.; UNDERSANDER, D.J.; CARTER, P.R. Agronomic evaluations of maize genotypes selected for extreme fiber concentrations. Crop Science, v.33, p.1359-1365, 1993.

Recebido em 3 de outubro de 2003 e aprovado em 17 de junho de 2004 